\title{
Efeito da adição de glutationa na função e estresse oxidativo em sêmen ovino criopreservado
}

\author{
Effect of glutathione on the function and oxidative status of ovine cryopreserved sperm
}

\author{
Eduardo Gualtieri de Andrade PEREZ; ${ }^{1}$ Marcilio NICHI'; Carlos Henrique Cabral VIANA ${ }^{2}$; Rodrigo \\ Otávio Correia da SILVA ${ }^{1}$; Andressa DALMAZZO ${ }^{1}$; Paola Almeida de Araújo GÓES ${ }^{1}$; \\ João Rafael Chinait GURGEL ${ }^{1}$; Valquiria Hyppolito BARNABE ${ }^{1}$; Renato Campanarut BARNABE ${ }^{1}$
}

\author{
${ }^{1}$ Departamento de Reprodução Animal da Faculdade de Medicina Veterinária e Zootecnia \\ da Universidade de São Paulo, São Paulo - SP, Brasil \\ ${ }^{2}$ Faculdade de Medicina Veterinária da Pontifícia Universidade Católica de Poços de Caldas, Poços de Caldas-MG, Brasil
}

\begin{abstract}
Resumo
Os ácidos graxos poli-insaturados garantem fluidez à membrana plasmática do espermatozoide. No entanto, as duplas ligações presentes, os tornam mais susceptíveis aos efeitos nocivos da peroxidação lipídica. A adição do antioxidante Glutationa reduzida (GSH) poderia conferir proteção aos espermatozoides de ovinos submetidos à congelação contra os graves danos causados pelo estresse oxidativo. O objetivo do presente experimento foi avaliar se a GSH protege os espermatozoides ovinos criopreservados contra danos causados pelo estresse oxidativo. Foram colhidos ejaculados de quatro carneiros adultos. As análises convencionais foram: concentração, motilidade, vigor e morfologia. As análises funcionais foram: integridade de membrana, integridade acrossomal, integridade de cromatina e atividade mitocondrial. O sêmen foi criopreservado utilizando o diluidor Tris-gema-critrato, suplementado com GSH (controle, 1, 5 e 10 $\mathrm{mM}$ ). As amostras foram submetidas ao protocolo de peroxidação lipídica induzida e subsequente quantificação das substâncias reativas ao ácido tiobarbitúrico (TBARS). As análises estatísticas foram realizadas utilizando o Sistema SAS para Windows. Não houve efeito do tratamento com GSH sobre as variáveis avaliadas pelos testes convencionais. A GSH diminuiu a proporção de acrossomas íntegros. Amostras tratadas com 5mM de GSH apresentaram menor percentual de células com membranas íntegras quando comparadas às amostras controle e aquelas tratadas com 10 mM; o percentual de células sem atividade mitocondrial foi influenciado pela GSH e também não houve efeito nas TBARS. As amostras do grupo controle foram mais susceptíveis à denaturação da cromatina. Em conclusão, a adição do antioxidante Glutationa reduzida confere proteção ao DNA e à atividade mitocondrial de espermatozoides de ovinos.
\end{abstract}

Palavras-chave: Ovinos. Criopreservação. Glutationa reduzida.

\begin{abstract}
The high susceptibility of sperm to the oxidative stress occurs especially due to high content of poly-unsaturated fatty acids (PUFAs) in its plasma membrane. The PUFAs provide the necessary fluidity to the plasma membrane. However double bonds present in those fatty acids are more susceptible to oxidative stress. Studies in human indicate that cryopreservation may lead to damages to the sperm due to oxidative stress. This study aimed to verify if the antioxidant glutathione (GSH) may protect ovine cryopreserved sperm against damages caused by oxidative stress. Semen samples of four rams were cryopreserved using Tris-egg yolk extender supplemented with different concentrations of reduced glutathione (control, 1, 5 and $10 \mathrm{mM}$ ). After thawing, samples were evaluated using conventional (motility and vigor) and functional tests (membrane integrity and mitochondrial activity). Aliquots of each thawed sample were submitted to protocol of induced lipid peroxidation using ascorbate $(20 \mathrm{mM})$ and ferrous sulphate $(4 \mathrm{mM})$, with further measurement of tiobarbituric acid reactive substances (TBARS), index of oxidative stress. No effect of GSH was observed on variables assessed by conventional tests. GSH decreased the proportion of intact acrosomes. Samples treated with $5 \mathrm{mM}$ GSH showed lower percentage of intact membrane cells when compared to control samples and those treated with $10 \mathrm{mM}$. The percentage of cells with mitochondrial activity was affected by GSH, but no effect on TBARS. Samples from control group were more susceptible to denaturation of chromatin. In conclusion, the addition of Glutathione (GSH) offers protection to DNA and mitochondrial activity of ovine sperm.
\end{abstract}

Keywords: Ovine. Cryopreservation. Reduced glutathione 


\section{Introdução}

A criopreservação de espermatozoides é uma biotecnologia de extrema importância para programas de inseminação artificial, pois viabiliza a utilização de reprodutores de localidades distantes, mesmo depois de mortos, uma vez que o sêmen estocado a $-196^{\circ} \mathrm{C}$ (temperatura do nitrogênio líquido) permanece viável por tempo indefinido ${ }^{1}$. Entretanto, o sucesso da criopreservação depende muito da susceptibilidade específica do espermatozoide a baixas temperaturas ${ }^{2}$. Resultados obtidos na criopreservação de sêmen de diversas espécies são muito diferentes entre si, devido às particularidades dos espermatozoides de cada espécie, principalmente, no que se refere à composição e estrutura de membranas biológicas ${ }^{3}$. Estudos anteriores relatam como principais danos causados pelo decréscimo da temperatura, alterações em membranas acrossomais, plasmática e em mitocôndrias, o que pode acarretar a liberação desordenada e exacerbada das espécies reativas de oxigênio as quais são potencialmente nocivas aos lipídios do sêmen ovino ${ }^{4}$.

A constituição lipídica do sêmen de carneiros é diferenciada da de outras espécies, sendo que os fosfolipídeos representam até $70 \%$ do total de lipídios da membrana espermática e $45 \%$ são plasmalogênios. Além disso, o espermatozoide ovino é distinto das demais espécies pela sua alta proporção de fosfoglicerídeos de colina ${ }^{5}$. Por outro lado, nos espermatozoides ovinos, $60 \%$ das ligações fosfolipídicas dos ácidos graxos são no carbono 22, sendo que, em espécies mais resistentes ao choque-frio, a proporção é de $30 \%$ das ligações. Ademais, os espermatozoides de carneiros contêm proporções menores de ácidos palmítico, esteárico e oléico ${ }^{6}$.

Além de sua constituição lipídica diferenciada, o sêmen ovino descongelado sofre uma capacitação prematura, em parte, relacionada à ligação de ROS (do inglês reactive oxigen species) e peroxidação lipídica. Um excesso de ROS também leva ao decréscimo da motilidade e fertilidade além de serem, também, deletérias ao DNA e membranas ${ }^{7}$. Assim, a adição de antioxidantes aos meios para criopreservação vem sendo adotada com o intuito de minimizar o estresse oxidativo e garantir melhor qualidade espermática após a descongelação8 .

Frente ao exposto, o objetivo do presente estudo foi: avaliar se a glutationa reduzida (GSH) protege os espermatozoides ovinos criopreservados contra danos causados pelo estresse oxidativo através da avaliação da integridade das membranas plasmáticas e acrossomais, da susceptibilidade do DNA espermático à denaturação, da atividade mitocondrial e da susceptibilidade dos espermatozoides ao estresse oxidativo induzido.

\section{Material e Método}

O presente experimento foi conduzido nas instalações da Pontifícia Universidade Católica de Minas Gerais, Campus de Poços de Caldas e no Laboratório de Andrologia do Departamento de Reprodução Animal da Faculdade de Medicina Veterinária e Zootecnia da Universidade de São Paulo, durante os meses de julho e agosto de 2009. Foram utilizados quatro carneiros (Ovis aries), adultos, sem raça definida. O sêmen foi colhido com auxílio de vagina artificial, sendo que, imediatamente após a obtenção de uma amostra, foi realizada análise a fim de se detectar eventuais alterações macroscópicas, tais como, presença de urina, sangue, ou outros sinais anormais. Em seguida, foi realizada uma análise microscópica, com a finalidade de qualificação do ejaculado quanto à presença de turbilhonamento e motilidade subjetiva maior ou igual a $70 \%$. Ejaculados que não obedecessem estas premissas foram descartados.

Os ejaculados obtidos de um animal foram divididos em quatro alíquotas iguais $(100 \mu \mathrm{L})$ e diluídos em meio Tris-gema citrato e glicerol a 7\% (Bovimix ${ }^{\oplus}$, Nutricell) com quatro concentrações diferentes de glutationa reduzida (GSH): $0 \mathrm{mM}$ (controle); $1 \mathrm{mM} ; 5 \mathrm{mM}$ e $10 \mathrm{mM}$. 
Após as alíquotas serem diluídas (50×10 espermatozoides por palheta) em seus respectivos meios, foram envasadas em palhetas de $0,5 \mathrm{~mL}$ e raqueadas. Posteriormente, foram submetidas a uma curva de resfriamento de $-0,2^{\circ} \mathrm{C} / \mathrm{min}$ até atingirem $5^{\circ} \mathrm{C}$ em geladeira convencional. Após uma hora de incubação, as raques foram acondicionadas sobre um suporte mantido a 4 centímetros do nitrogênio líquido em caixa de isopor por 20 minutos. Decorrido este tempo, as palhetas foram imersas no nitrogênio e estocadas em botijão criogênico.

As amostras foram descongeladas em banho-maria, a $37^{\circ} \mathrm{C}$ por 30 segundos e, seguidamente, submetidas à centrifugação a $800 \mathrm{x}$ g por 5 minutos e foram ressuspensas em PBS para a remoção do diluidor. Este procedimento foi realizado duas vezes antes das amostras serem processadas com a finalidade de isolar possíveis substratos para oxidação, constituintes do meio para criopreservação (por exemplo: gema de ovo), de modo a prevenir que os resultados fossem mascarados pela peroxidação de lipídios não inerentes aos espermatozoides.

As avaliações convencionais empregadas neste trabalho foram: motilidade e vigor e morfologia espermática ${ }^{2}$.

Visando monitorar os possíveis danos causados durante a congelação das amostras, a técnica de esfregaço corado com Faste-green/ Rosa Bengala descrita por Pope, Zhang e Dresser ${ }^{9}$ foi utilizada para a avaliação da integridade estrutural da membrana acrossomal (acrossomas corados de azul escuro: íntegros / acrossomas não corados: não íntegros). Para a avaliação da integridade da membrana plasmática, foi utilizado o esfregaço corado com Eosina-Nigrosina $(\mathrm{E} / \mathrm{N})^{10}$. A atividade citoquímica da mitocôndria espermática foi aferida por incubação com 3-3' -diaminobenzidina descrita por Hrudka ${ }^{11}$. Desta maneira, as lâminas foram observadas em microscópio de contraste de fase, sob aumento de 1000 vezes, em imersão. Foram contados 200 espermatozoides/lâmina e classificados, de acordo com a quantidade de corante visualizada na peça intermediária, em quatro classes:

Classe I: células espermáticas com peça intermediária totalmente corada, alta atividade mitocondrial (DAB I);

Classe II: células espermáticas com segmentos corados (ativos) e não-corados (inativos), havendo predominância dos ativos (DAB II);

Classe III: células espermáticas com segmentos corados (ativos) e não-corados (inativos), havendo predominância dos inativos (DAB III);

Classe IV: células espermáticas com peça intermediária totalmente descorada, sem atividade mitocondrial (DAB IV).

A avaliação da susceptibilidade da cromatina à fragmentação foi realizada pelo Ensaio SCSA, proposto por Evanson et al. ${ }^{12}$. Para esta, uma palheta de sêmen de cada tratamento foi avaliada.

A avaliação da peroxidação lipídica foi realizada com base na metodologia proposta por Ohkawa, Ohishi e Yagi ${ }^{13}$, que tem como fundamento a reação de duas moléculas de ácido tiobarbitúrico com uma molécula de malondialdeído (MDA), subproduto da peroxidação de lipídeos. Foi empregado um sistema gerador de ROS com posterior mensuração da concentração de espécies reativas ao ácido tiobarbitúrico (TBARS) através da espectrofotometria, mensurando-se, portanto, a susceptibilidade das células à peroxidação lipídica. A concentração de TBARS foi quantificada através de leitura em espectrofotômetro, num comprimento de onda de $532 \mathrm{~nm}$. Os resultados foram comparados com uma curva padrão, feita previamente, com malondialdeído. A concentração de TBARS nas amostras foi expressa em nanogramas de TBARS por $1 \times 106$ espermatozoides (ng/106 sptz).

Os dados foram analisados por meio do programa SAS System for Windows (2000). Diferenças significantes foram avaliadas através do teste Least Square Differences (LSD). Para descrição dos resultados, foram empregados os erros padrões das médias e as 
médias (média \pm erro padrão da média). $\mathrm{O}$ nível de significância utilizado para rejeitar H0 (hipótese de nulidade) foi de 5\%. Foi utilizada também a correlação de Pearson, sendo os resultados expressos através do coeficiente de correlação (r) e seu nível de significância (p).

\section{Resultados e Discussão}

Os resultados encontrados no presente estudo indicam que não houve efeito do tratamento com GSH sobre as variáveis avaliadas através dos testes funcionais (e.g., motilidade, vigor e defeitos espermáticos; Tabela 1).

Pode-se observar que as amostras tratadas com $5 \mathrm{mM}$ de GSH apresentaram menor percentual de cé- lulas com membranas íntegras quando comparadas com as amostras controle e aquelas tratadas com 10 $\mathrm{mM}(9,22 \pm 1,32,15,06 \pm 2,35$ e $18,31 \pm 2,15 \%$, respectivamente; Tabela 2 ).

Com relação à integridade acrosomal, o emprego das concentrações de 1 e $5 \mathrm{mM}$ de GSH diminuiu a proporção de acrossomas íntegros em relação ao controle $(60,40 \pm 3,75,59,09 \pm 4,10$ e $69,84 \pm 2,31 \%$, respectivamente; Tabela 2). Estes resultados, assim como os encontrados para as variáveis avaliadas através dos testes convencionais, contrariaram nossa hipótese de que o tratamento com GSH ao diluidor melhoraria a qualidade espermática pós-criopreservação. Uma possível explicação para estes resultados seria que a GSH não estaria envolvida na destruição das ROS relacionadas aos danos causados pela criopreservação

Tabela 1 - Efeito do tratamento com diferentes concentrações de GSH $(1 \mathrm{mM}, 5 \mathrm{mM}$ e $10 \mathrm{mM})$ em sêmen ovino criopreservado sobre a motilidade, vigor, defeitos maiores, menores e totais - São Paulo - 2009 (n=24)

\begin{tabular}{ccccc}
\cline { 2 - 5 } & \multicolumn{4}{c}{ Concentração de GSH } \\
\cline { 2 - 5 } & Controle & $1 \mathrm{mM}$ & $5 \mathrm{mM}$ & $10 \mathrm{mM}$ \\
\hline Motilidade (\%) & $38,44 \pm 4,25^{\mathrm{a}}$ & $29,69 \pm 3,75^{\mathrm{a}}$ & $28,44 \pm 3,18^{\mathrm{a}}$ & $36,56 \pm 4,87^{\mathrm{a}}$ \\
Vigor (1-5) & $2.97 \pm 0,23^{\mathrm{a}}$ & $2,37 \pm 0,24^{\mathrm{a}}$ & $2,69 \pm 0,20^{\mathrm{a}}$ & $2,94 \pm 0,18^{\mathrm{a}}$ \\
Defeitos maiores (\%) & $5,31 \pm 0,45^{\mathrm{a}}$ & $5,31 \pm 0,45^{\mathrm{a}}$ & $5,06 \pm 0,46^{\mathrm{a}}$ & $4,81 \pm 0,46^{\mathrm{a}}$ \\
Defeitos menores (\%) & $6,44 \pm 0,81^{\mathrm{a}}$ & $6,44 \pm 0,81^{\mathrm{a}}$ & $7,00 \pm 0,79^{\mathrm{a}}$ & $7,56 \pm 0,76^{\mathrm{a}}$ \\
Defeitos totais (\%) & $11,75 \pm 0,92^{\mathrm{a}}$ & $11,75 \pm 0,92^{\mathrm{a}}$ & $12,06 \pm 0,91^{\mathrm{a}}$ & $12,37 \pm 0,90^{\mathrm{a}}$ \\
\hline
\end{tabular}

a, Letras diferentes na mesma linha indicam diferenças estatísticas (LSD, p<0,05)

Tabela 2 - Efeito do tratamento com diferentes concentrações de GSH $(1 \mathrm{mM}, 5 \mathrm{mM}$ e $10 \mathrm{mM})$ em sêmen ovino criopreservado sobre a integridade de membrana (Vitalidade), integridade de acrossomo (ACRO), atividade mitocondrial (DAB I, II, III e IV) e fragmentação de DNA (SCSA) - São Paulo - 2009 $(\mathrm{n}=24)$

\begin{tabular}{ccccc}
\cline { 2 - 4 } & \multicolumn{3}{c}{ Concentração de GSH } \\
\cline { 2 - 4 } & Controle & $1 \mathrm{mM}$ & $5 \mathrm{mM}$ & $10 \mathrm{mM}$ \\
\hline Vitalidade (\%) & $15,06 \pm 2,35^{\mathrm{a}}$ & $13,07 \pm 1,95^{\mathrm{ab}}$ & $9,22 \pm 1,32^{\mathrm{b}}$ & $18,31 \pm 2,15^{\mathrm{a}}$ \\
ACRO (\%) & $69,84 \pm 2,31^{\mathrm{a}}$ & $60,40 \pm 3,75^{\mathrm{a}}$ & $59,09 \pm 4,10^{\mathrm{b}}$ & $62,59 \pm 2,70^{\mathrm{ab}}$ \\
DAB I (\%) & $64,12 \pm 3,75^{\mathrm{a}}$ & $69,70 \pm 3,58^{\mathrm{a}}$ & $60,00 \pm 5,57^{\mathrm{a}}$ & $67,09 \pm 3,87^{\mathrm{a}}$ \\
DAB II (\%) & $16,59 \pm 1,81^{\mathrm{a}}$ & $14,73 \pm 1,81^{\mathrm{a}}$ & $20,75 \pm 2,6^{\mathrm{a}}$ & $19,53 \pm 2,44^{\mathrm{a}}$ \\
DAB III (\%) & $9,75 \pm 1,24^{\mathrm{a}}$ & $8,57 \pm 1,21^{\mathrm{a}}$ & $7,31 \pm 0,92^{\mathrm{a}}$ & $6,50 \pm 1,01^{\mathrm{a}}$ \\
DAB IV (\%) & $9,53 \pm 1,45^{\mathrm{a}}$ & $7,00 \pm 1,57^{\mathrm{a}}$ & $7,00 \pm 1,30^{\mathrm{ab}}$ & $6,87 \pm 1,40^{\mathrm{b}}$ \\
SCSA (\%) & $12,32 \pm 1,54^{\mathrm{a}}$ & $9,07 \pm 1,52^{\mathrm{b}}$ & $7,85 \pm 1,07^{\mathrm{b}}$ & $6,64 \pm 0,62^{\mathrm{b}}$ \\
\hline
\end{tabular}

a, b Letras diferentes na mesma linha indicam diferenças estatísticas (LSD, p<0,05) 
aos acrossomas e membranas. Além disso, os danos ocorridos em acrossomas e membranas podem não ser resultado da ação das ROS. A injúria observada poderia ser devido à formação de cristais de gelo, os quais causariam danos mecânicos às estruturas espermáticas ${ }^{14}$. Neste caso, o tratamento do meio para criopreservação com GSH não forneceria qualquer proteção aos acrossomas e membranas. Além disso, estas estruturas estão sempre em contato com o meio extracelular. O plasma seminal conta com maquinaria enzimática para proteção antioxidante oriunda do epitélio epididimário, principalmente, composta pela SOD e $\mathrm{Gpx}^{15}$. No entanto, para a criopreservação, faz-se necessária a diluição do sêmen com meio extensor o que leva a consequente diluição dos antioxidantes presentes. Visto que o principal efeito antioxidante da GSH é como substrato da enzima selênio-dependente $\mathrm{Gpx}^{16}$, nas amostras criopreservadas, as baixas concentrações desta enzima seriam um fator limitante para a atuação da GSH. Tal fato seria ainda mais deletério uma vez que o sistema Gpx-GSH seria o responsável pela destruição do peróxido de hidrogênio, evitando assim a formação do radical hidroxila, a ROS mais potencialmente reativa. Talvez o emprego de concentrações maiores que 10mM GSH concomitantemente com a adição de Gpx, exerceria efeito positivo sobre a integridade das membranas e acrossomais.

Quanto à atividade mitocondrial (DAB), os tratamentos não exerceram efeito sobre o percentual de células classe I, II e III. No entanto, o percentual de células sem atividade mitocondrial (DAB IV) foi influenciado pela GSH; o grupo controle apresentou maior porcentagem de células sem atividade quando comparado ao grupo tratado com $10 \mathrm{mM}(9,53 \pm$ 1,45 e 6,87 $\pm 1,40 \%$, respectivamente; Tabela 2). Da mesma forma, as amostras do grupo controle foram mais susceptíveis à denaturação da cromatina quando comparadas com as amostras tratadas com $10 \mathrm{mM}$ de GSH $(12,32 \pm 1,54$ e 6,64 \pm 0,62\%, respectivamente; Tabela 2). Embora os tratamento com 1 e $5 \mathrm{mM}$ não tenham diferido do controle $(9,07 \pm 1,52,7,85 \pm 1,07$ e $12,32 \pm 1,54 \%$, respectivamente; Tabela 2 ), pode-se observar um efeito dose-dependente de GSH sobre a susceptibilidade da cromatina à denaturação, isto é, quanto maior a concentração de GSH utilizada, mais resistentes as células estariam.

$\mathrm{O}$ emprego de GSH influenciou positivamente a integridade mitocondrial bem como a resistência da cromatina a denaturação. Segundo Chaudiere e Ferrari-Iliou ${ }^{17}$, a Gpx é a enzima antioxidante mais abundante em mitocôndrias e citoplasma. Assim, o tratamento com GSH foi eficiente nos ambientes com maiores concentrações de Gpx. Resultados semelhantes foram encontrados por Baumber et al. ${ }^{18}$ em amostras espermáticas de garanhões tratadas com $10 \mathrm{mM}$ de GSH. Neste experimento, os autores verificaram, por meio do ensaio cometa, o efeito protetor da GSH sobre o DNA exposto a um sistema de geração de ROS.

Apesar da tendência dose-dependente do tratamento com as diferentes concentrações de GSH sobre as substâncias reativas ao ácido tiobarbitúrico (TBARS), tanto da produção total como a calculada por espermatozoides (Tabela 3), não foi observado efeito significativo deste tratamento.

A técnica de TBARS visa mensurar o subproduto do ataque das ROS a lipídeos, encontrado no ambiente extracelular ${ }^{19}$. Assim, quando este ataque ocorre em componentes de natureza não-lipídica (por exemplo: proteínas, carboidratos e DNA), ou no meio intracelular, esta técnica pode não ser eficiente. Como pudemos verificar na avaliação convencional e funcional do sêmen, a GSH apresentou um efeito benéfico, apenas para a atividade mitocondrial e para a susceptibilidade da cromatina espermática à denaturação, variáveis relacionadas ao meio intracelular. Desta forma, baseando-se nestes resultados e na ausência de efeitos da GSH nas TBARS, podemos inferir que, nas amostras criopreservadas de ovinos, o estresse oxidativo foi mais importante no meio intracelular. 
Tabela 3 - Efeito do tratamento com diferentes concentrações de GSH (1mM, $5 \mathrm{mM}$ e $10 \mathrm{mM}$ ) sobre a produção total de substâncias reativas ao ácido tiobarbitúrico (TBARS, $\mathrm{ng} / \mathrm{mL}$ ) e sobre a produção de substâncias reativas ao ácido tiobarbitúrico (TBARS, ng/106 sptz) em sêmen ovino criopreservado submetido ao desafio oxidativo pelo ascorbato e o sulfato ferroso - São Paulo - $2009(n=24)$

\begin{tabular}{crrrr}
\cline { 2 - 4 } & \multicolumn{4}{c}{ Concentração de GSH } \\
\cline { 2 - 5 } & Controle & $1 \mathrm{mM}$ & $5 \mathrm{mM}$ & $10 \mathrm{mM}$ \\
\hline TBARS (ng/mL) & $1292,9 \pm 252,6^{\mathrm{a}}$ & $1213,7 \pm 117,8^{\mathrm{a}}$ & $1145,1 \pm 107,2^{\mathrm{a}}$ & $883,1 \pm 54,3^{\mathrm{a}}$ \\
TBARS (ng/10 $\mathrm{sptz})$ & $19,99 \pm 5,27^{\mathrm{a}}$ & $16,12 \pm 2,18^{\mathrm{a}}$ & $15,15 \pm 2,29^{\mathrm{a}}$ & $11,23 \pm 1,66^{\mathrm{a}}$ \\
\hline
\end{tabular}

a, b Letras diferentes na mesma linha indicam diferenças estatísticas (LSD, $\mathrm{p}<0,05$ )

Foi observada uma correlação positiva $(r=0,35$, $\mathrm{p}=0,02$; Tabela 4) entre TBARS (ng/ $\left.10^{6} \mathrm{sptz}\right)$ e SCSA. Apesar de, à primeira vista, este resultado levar a crer que houve correlação entre estresse oxidativo e fragmentação de DNA, é importante salientar que ambas as técnicas submetem os espermatozoides a desafio, não representando valores reais e fisiológicos. Este resultado indica que células mais susceptíveis ao estresse oxidativo seriam mais propensas a lesões em DNA.

Uma explicação para as correlações negativas encontradas entre a porcentagem de células com membrana íntegra, tanto com TBARS (ng/10 $10^{6} \mathrm{stz} ; \mathrm{r}=-$ $0,39, \mathrm{p}=0,02)$ como com SCSA ( $\mathrm{r}=-32, \mathrm{p}=0,03)$, seria que células com membrana lesada estariam mais propensas ao ataque das ROS e também, a lesão da cromatina. Além disso, foram verificadas fortes correlações entre células com membrana íntegra e atividade mitocondrial (DAB I: $\mathrm{r}=0,51, \mathrm{p}=0,0002$; $\mathrm{DAB}$ II: $r=-0,38, p=0,0092$; DAB III: $r=-0,37, p=0,014$ e DAB IV: $r=-0,35, p=0,017)$. Uma hipótese para explicar estes resultados seria as mitocôndrias de células com membrana lesada estarem mais sujeitas a lesões, o que levaria a liberação de fatores pró-oxidativos e pró-apoptóticos. Caso estas células fossem submetidas a um estresse adicional, ocorreria um ataque mais agressivo ao DNA e mesmo a células vizinhas. Da mesma forma, Blumer et al. ${ }^{20}$ também verificaram uma relação entre fragmentação de DNA e atividade mitocondrial defectiva. Segundo estes autores, existe uma estreita relação entre a disfunção da atividade mitocondrial causada pelo estresse oxidativo e a fragmentação de DNA.

Verificou-se que a motilidade correlacionou-se com a porcentagem de células DAB III $(r=-0,36, p=0,015)$ e com a porcentagem de células com membrana íntegra $(r=0,45, p=0,0013)$. Isto comprovaria a influência negativa da atividade mitocondrial altamente comprometida, possivelmente exacerbada pela lesão de membrana que, por sua vez, levaria o decréscimo da motilidade. Da mesma forma, as correlações encontradas entre vigor e motilidade com o SCSA $(r=-0,35$, $\mathrm{p}=0,016$ e $\mathrm{r}=-0,29, \mathrm{p}=0,047$, respectivamente) indicariam que células com comprometimento da cromatina, possivelmente causado pelos eventos citados anteriormente, apresentariam lesões oxidativas tão extensas que levariam então à diminuição de motilidade e vigor. Estes resultados indicam que, provavelmente, a lesão de cromatina seria um dos últimos eventos causados pelo estresse oxidativo.

A adição do antioxidante Glutationa reduzida (GSH) confere proteção ao DNA e à atividade mitocondrial de espermatozoides de ovinos submetidos a criopreservação contra danos causados pelo estresse oxidativo. 


\section{Referências}

1. HAFEZ, B.; HAFEZ, E. S. E. Reprodução animal. São Paulo: Manole, 2004. p. 381-382. 2004.

2. HOLT, W. V. Basic aspects of frozen storage of semen. Animal Reproduction Science,v. 62, n. 3, p. 3-22, 2000.

3. DARIN-BENNETT, A.; WHITE, I. G. Influence of the cholesterol content of mammalian spermatozoa on susceptbility to cold-shock. Cryobiology, v. 14, n. 1, p. 466-470, 1977.

4. OLLERO, M.; PEREZ-PE, R.; MUNIÑO-BLANCO, T.; CEBRIAN-PEREZ, J. A. Improovement of ram sperm cryopreservation protocols assessed by heterogeneit análisis. Cryobiology, v. 37, n. 1 p. 1-12, 1998.

5. WATSON, P. F. The effects of cold shock on sperm cell membranes. The effects of low temperatures on biological elements, v. 1, n. 1, p. 189-218, 1981.

6. WATSON, P. F. Recent developments and concepts in the cryopreservation of spermatozoa and the assessment of their post-thawing function. Journal of Reproduction and Fertility, v. 7, n. 4, p. 871-891, 1995.

7.AISEN, E.; QUINTANA, M.; MEDINA, V.; MORELLO, H.; VENTURINO, A. Ultramicroscopic and biochemical changes in ram spermatozoa cryopreserved with trehalose based hypertonic extenders. Cryobiology, v. 50, n. 3, p. 239-249, 2005.

8. DONNELLY, E. T.; MCCLURE, N.; LEWIS, S. E. M. Antioxidant supplementation in vitro does not improve human sperm motility. Fertility and Sterility, v. 72, n. 3, p. 484-495, 1999.

9. POPE, C. E.; ZHANG, Y. Z.; DRESSER, B. L. A simple staining method for evaluating acrosomal status of cat spermatozoa. Journal of Zoo and Wildlife Medicine, v. 22, n. 1, p. 87-95, 1991.

10. BARTH, A. D.; OKO, R. J. Abnormal morphology of bovine spermatozoa. Ames: Iowa State University Press, 1989. 285 p.

11. HRUDKA, F. Cytochemical and ultracytochemical demonstration of cytochrome-c oxidase in spermatozoa and dynamics of changes accompanying ageing or induced by stress. International Journal of Andrology, v.
10, n. 6, p. 809-828, 1987.

12.EVANSON, D. P.; JOST, L. K.; MARSHALL, D.; ZINAMAN, M. J.; CLEGG, E.; PURVIS, K.; DE ANGELIS, P.; CLAUSSEN, O. P. Utility of the sperm chromatin structure assay as a diagnostic and prognostic tool in the human fertility clinic. Human Reproduction, v. 14, n. 4, p. 1039-1049, 1999.

13. OHKAWA, H.; OHISHI, N.; YAGI, K. Assay for lipid peroxides in animal tissues by thiobarbituric acid reaction. Analytical Biochemistry, v. 95, n. 3, p. 351-358, 1979.

14.SARAGUSTY, J.; GACITUA, H.; ROZENBOIM, I.; ARAV, A. Protective effects of iodixanol during bovine sperm cryopreservation. Theriogenology, v. 71, n. 9, p. 1425-1432, 2009.

15. MARTI, E.; MARA, L.; MARTI, J. I.; MUINO-BLANCO, T.; CEBRIAN-PEREZ, J. A. Seasonal variations in antioxidant enzyme activity in ram seminal plasma. Theriogenology, v. 67, n. 9, p. 1446-1454, 2007.

16. HALLIWELL, B.; GUTTERIDGE, J. M. C. Free radicals in biology and medicine. Oxford: Editora Oxford, 1989. 543 p.

17.CHAUDIERE, J.; FERRARI-ILIOU, R. Intracellular Antioxidants: from Chemical to Biochemical Mechanisms. Food and Chemical Toxicology, v. 37, n. 9, p. 949-962, 1999.

18. BAUMBER, J.; BALL, B. A.; LINFOR, J. J.; MEYERS, S. A. Reactive Oxygen Species and Cryopreservation Promote DNA Fragmentation in Equine Spermatozoa. Journal of Andrology, v. 24, n. 4, p. 621-628, 2003.

19.NICHI, M.; BOLS, P. E. J.; ZUGE, R. M.; BARNABE, V. H.; GOOVAERTS, I. G. F.; BARNABE, R. C.; CORTADA, C. N. $M$. Seasonal variation in semen quality in Bos indicus and Bos taurus bulls raised under tropical conditions. Theriogenology, v. 66, n. 4 , p. 822-828, 2006.

20. BLUMER, C. G.; FARIELLO, R. M.; RESTELLI, A. E.; SPAINE, D. M.; BERTOLLA, R. P.; CEDENHO, A. P. Sperm nuclear DNA fragmentation and mitochondrial activity in men with varicocele. Fertility and Sterility, v. 90, n. 5, p. 1716-1722, 2007. 